\title{
IMPROVEMENT OF THE ANTIFUNGAL ACTIVITY AGAINST BOTRYTIS CINEREA OF SYRINGIC ACID, A PHENOLIC ACID FROM GRAPE POMACE
}

\author{
LEONORA MENDOZA*, PAULO CASTRO, RICARDO MELO, ANA MARÍA CAMPOS, GUSTAVO ZÚÑIGA, \\ JUAN GUERRERO, AND MILENA COTORAS*
}

Facultad de Química y Biología, Universidad de Santiago de Chile. Alameda 3363, Estación Central, Santiago, Chile.

\begin{abstract}
The aim of this study was to improve the antifungal activity against Botrytis cinerea of syringic acid by using the enzyme laccase to synthesize a heterodimeric compound by a coupling reaction with aniline. The synthesized heterodimer is a quinone-imine like compound (2,6-dimethoxy-4-(phenylimino)benzenone), which was characterized by using ${ }^{1} \mathrm{H}$ and ${ }^{13} \mathrm{C}$ NMR, IR, and mass spectrometry. The antifungal activity of the heterodimeric compound against $B$. cinerea was determined in vitro and showed a higher antifungal effect than the substrates (syringic acid and aniline), inhibiting the mycelial growth with an $\mathrm{IC}_{50} \mathrm{value}$ of $0.14 \mathrm{mM}$ and delayed 2 hours the conidial germination. Also, using the fluorochrome calcofluor white, cell wall damage was observed when $B$. cinerea was incubated with the compound. This is the first report on antifungal activity of this type of compound against $B$. cinerea.
\end{abstract}

Keywords: Botrytis cinerea; antifungal activity; laccase; 2,6-dimethoxy-4-(phenylimino)benzenone.

\section{INTRODUCTION}

Botrytis cinerea is a ubiquitous fungus which causes Grey Rot disease on many different economically important crops like tomato, cucumber, rose, grapevine, strawberry, etc. This pathogen attacks many organs, stems, fruits and flowers causing great economic losses especially in post-harvest period ${ }^{1}$.

$B$. cinerea is mainly managed with synthetic fungicide. These fungicides are becoming less accepted due to the increase of resistant strains and environmental pollution ${ }^{1,2}$. Therefore, natural products isolated from plants are an alternative to synthetic fungicides. Terpenoids, phenolic compounds, nitrogen-containing compounds, and aliphatic compounds isolated from plants have shown antifungal properties ${ }^{3-5}$. Grape pomaces are an important source of phenolic compounds ${ }^{6}$. It has been reported that extracts obtained from grape pomaces present antifungal activity against $B$. cinerea. However, pure compounds identified in these extracts showed low antifungal effect 7. Numerous authors have reported that the biological activity of phenolic compounds can be improved modifying phenolic molecules by using the enzyme laccase (EC 1.10.3.2) a polyphenol oxidase ${ }^{8}$. Antioxidant, antitumor, and anti-depressive compounds have been synthesized using this enzyme ${ }^{8-11}$. Additionally, this enzyme has been recently used for the synthesis of antifungal compounds ${ }^{12}$.

Laccase is a copper-containing oxidase that catalyzes reduction of molecular oxygen to water and the oxidation of a phenolic compound ${ }^{13}$. Also, dimerization, oligomerization, and polymerization of phenolic compounds can be obtained ${ }^{8}$. This enzyme has been used to synthesize hydroxybiphenyl dimers ${ }^{14}$, isoeugenol dimers ${ }^{15}$, and ferulic acid dimers ${ }^{16}$. Laccase is also able to couple a laccase substrate with a non-laccase substrate (known as a mediator) to create new molecules (heterodimers) ${ }^{8,17}$. Niedermeyer et al. reported the heterodimeric synthesis among $\mathrm{p}$-hydroquinones and primary aromatic amines using laccase ${ }^{10}$. Another example is the coupling between p-hydroquinones with p-aminobenzoic acid ${ }^{18}$. On the other hand, modification of antibiotics using laccase coupling reactions produced compounds with lower activities ${ }^{19}$, however, using nitrogen compounds to modify the antibiotics, the synthesized products showed higher antibacterial activities 20,21 . The anticancer activity of naphtohydroquinones has been improved by nuclear monoamination with anilines using laccase ${ }^{22}$. These results indicate that the laccase-mediated amination of a phenolic compound could increase the biological activity.

The aim of this work was to improve the antifungal activity against $B$. cinerea of one phenolic acid found in grape pomace (syringic acid) through the laccase-catalyzed synthesis of a heterodimeric compound with aniline. In addition, the effect of synthetized product on the cell wall and plasmatic membrane integrity of $B$. cinerea was analyzed.

\section{EXPERIMENTAL}

\subsection{General experimental procedures.}

The NMR spectra were acquired using a Bruker Avance $400 \mathrm{MHz}$ spectrometer $\left(400,133 \mathrm{MHz}\right.$ for ${ }^{1} \mathrm{H}, 100.624 \mathrm{MHz}$ for $\left.{ }^{13} \mathrm{C}\right)$. All measurements were performed in $\mathrm{CDCl}_{3}$ to $300 \mathrm{~K}$. Chemical shifts (in ppm) for ${ }^{1} \mathrm{H}$ and ${ }^{13} \mathrm{C}$ spectra, were calibrated to solvent signal, $\mathrm{CHCl}_{3} 7.26 \mathrm{ppm}$ (residual signal solvent) and $77.16 \mathrm{ppm}$, respectively, and reported relative to $\mathrm{Me}_{4} \mathrm{Si}$. Thinlayer chromatography was performed on Merck Kiesegel 60 F254, $0.2 \mathrm{~mm}$ thick and semi-preparative thin layer chromatography on Merck Kieselgel 60 $\mathrm{F}_{254} 20 \mathrm{x} 20 \mathrm{~cm} \times 0.25 \mathrm{~mm}$. The mass spectrum of the compound was acquired using a mass spectrometer Shimadzu-GCMS-Q5050 instrument using direct inlet system. The scan covered the mass range $(\mathrm{m} / \mathrm{z})$ from 150 to $350 \mathrm{~m} / \mathrm{z} 243$ $\left[\mathrm{M}^{+}\right] \mathrm{C}_{14} \mathrm{H}_{13} \mathrm{NO}_{3}$.

\subsection{Chemicals reagents and compounds used in this study.}

Technical grade fungicide iprodione [3-(3,5-dichlorophenyl)- $N$-isopropyl2,4-dioxoimidazolidine-1-carboxamide] was provided from INIA (Santiago, Chile).

Syringic acid, aniline, and the enzyme laccase used in this study were obtained commercially, Sigma Chemical Co. (St. Louis, MO)

2.3. Laccase-mediated synthesis of 2,6-dimethoxy-4-(phenylimino) benzenone (compound 1)

Three different syringic acid:aniline ratios (1:1, 1:2 and 2:1) and three different enzyme amounts $(2.25,4.5$ and $9 \mathrm{U})$ were tested in order to increase the quantity of the heterodimeric compound synthesized. For the 1:1 syringic acid:aniline ratio, both compounds were dissolved in $1 \mathrm{~mL}$ ethyl acetate $(0.05 \mathrm{mM}$ each), and the enzyme was dissolved in $1 \mathrm{~mL}$ sodium acetate buffer $(50 \mathrm{mM})$ at $\mathrm{pH} 4.5$. Both solutions were mixed and the reaction mixture was stirred at $100 \mathrm{rpm}$ during 180 minutes at $22^{\circ} \mathrm{C}$. After this time, the solvent was evaporated using a rotary evaporator at $40{ }^{\circ} \mathrm{C}$. The heterodimeric compound was purified from the reaction mixture that also contained secondary products, substrates, and the enzyme, by using semi-preparative thin layer chromatography (TLC silica gel $60 \mathrm{~F}_{254}$ glassplates $20 \times 20 \mathrm{~cm}$ ) with hexane:ethyl acetate $(1: 1)$ as an eluent system. Compound 1 showed a Rf of 0.3 . Since compound 1 has a yellow color, no revelation of the TLC was needed.

Compound 1 Yield 67.8\%, IR $(\mathrm{KBr}) \vee 1635(\mathrm{C}=\mathrm{N}) \mathrm{cm}^{-1},{ }^{1} \mathrm{H}$ and ${ }^{13} \mathrm{C}$ NMR spectra were recorded using a Bruker Avance RW- 400 spectrometer, deuterated acetone $\left(\mathrm{CD}_{3} \mathrm{COCD}_{3}\right)$ was used as solvent. ${ }^{1} \mathrm{H}$ NMR $\left(\mathrm{CD}_{3} \mathrm{COCD}\right.$ $400 \mathrm{MHz}) \delta 3.624$ (s, 3H, Hg), $3.872(\mathrm{~s}, 3 \mathrm{H}, \mathrm{Hf}), 6.158(\mathrm{~d}, 1 \mathrm{H}, \mathrm{He}), 6.423$ (d, $1 \mathrm{H}, \mathrm{Hd}), 6.898(\mathrm{~d}, 2 \mathrm{H}, \mathrm{Hc}), 7.407(\mathrm{t}, 2 \mathrm{H}, \mathrm{Hb}), 7.177(\mathrm{t}, 1 \mathrm{H}, \mathrm{Ha}) ;{ }^{13} \mathrm{C} \mathrm{NMR}$ $\left(\mathrm{CD}_{3} \mathrm{COCD}_{3}, 100 \mathrm{MHz}\right) \delta 57.076(\mathrm{CH} 3), 57.351(\mathrm{CH} 3), 177.436(\mathrm{C} 1), 157.51$ (C2), 156.716 (C6), 100.234 (C3), 113.326 (C5), 158.862 (C4), 152.615 (C1'), 122.339 (C2'), 130.802 (C3'), 126.458 (C4'). 


\subsection{Fungal strain and culture conditions}

The strain G29 of B. cinerea was used; it was isolated originally from grapes (Vitis vinifera) by the Instituto de Investigaciones Agropecuarias La Platina, Chile and is genetically characterized ${ }^{23}$. It was maintained on maltyeast extract agar slants with $(2 \%(\mathrm{w} / \mathrm{v})$ malt extract, $0.2 \%(\mathrm{w} / \mathrm{v})$ yeast extract and $1.5 \%(\mathrm{w} / \mathrm{v})$ agar) at $4{ }^{\circ} \mathrm{C}$. In studies on the effect of the compound on the cell wall and the plasmatic membrane integrity, liquid minimum medium was used, composed by $\mathrm{KH}_{2} \mathrm{PO}_{4}(1 \mathrm{~g} / \mathrm{L}), \mathrm{K}_{2} \mathrm{HPO}_{4}(0.5 \mathrm{~g} / \mathrm{L}), \mathrm{MgSO}_{4}$ x $7 \mathrm{H}_{2} \mathrm{O}(0.5$ $\mathrm{g} / \mathrm{L}), \mathrm{KCl}(0.5 \mathrm{~g} / \mathrm{L}), \mathrm{FeSO}_{4} \times 7 \mathrm{H}_{2} \mathrm{O}(0.01 \mathrm{~g} / \mathrm{L}) \mathrm{pH} 6.5,25 \mathrm{~mol} / \mathrm{L}$ ammonium tartrate as a nitrogen source, and $1 \%(\mathrm{w} / \mathrm{v})$ glucose as carbon source.

\subsection{Antifungal Assay}

2.5.1. Effect on mycelial growth.

The effect of compound $\mathbf{1}$ and the substrates (syringic acid and aniline) on mycelial growth of $B$. cinerea was assessed in vitro using the radial growth test on malt-yeast extract agar ${ }^{24}$. Synthesized compound, syringic acid, and aniline dissolved in acetone at different concentrations $(0.1 \mathrm{mM}$ to $0.4 \mathrm{mM}$ for compound 1 and $1 \mathrm{mM}$ to $5 \mathrm{mM}$ for syringic acid and aniline) were added to Petri dishes containing a malt-yeast extract agar medium. The final acetone concentration was identical in the control and treatment assays. Commercial fungicide iprodione was used as a control. After evaporation of the acetone in a laminar flow cabinet, the culture medium was inoculated with $0.5 \mathrm{~cm}$ agar disks from an actively growing culture of $B$. cinerea. Cultures were incubated in the dark at $22{ }^{\circ} \mathrm{C}$ for seven days. Mycelial growth diameters were measured daily. Results were expressed as $\mathrm{IC}_{50}$ (the concentration that reduced mycelial growth by $50 \%$ ), determined by the inhibition of radial growth against compound concentrations. Each experiment was done at least three times.

\subsubsection{Effect on conidial germination.}

Conidial germination assay was carried out as described by Cotoras et al ${ }^{25}$ using the synthesized compound, syringic acid, or aniline dissolved in acetone at a final concentration of $0.16 \mathrm{mM}$. The final acetone concentration was identical in the control and treatment assays.

\subsection{Effect on B. cinerea cell wall integrity}

The effect of compound $\mathbf{1}$ on the cell wall integrity was determined using fluorochrome calcofluor white. B. cinerea conidia at a final concentration of $1 \times 10^{5}$ conidia $\mathrm{mL}^{-1}$ were inoculated in 24-well plates (lined with 12$\mathrm{mm}$ glass coverslips) containing $1 \mathrm{~mL}$ of liquid minimum medium. Cultures were incubated at $22^{\circ} \mathrm{C}$ for $15 \mathrm{~h}$ to permit the germination of the conidia. After this time, liquid medium was removed. Afterwards, liquid medium containing: lysing enzymes (positive control), $10 \%(\mathrm{v} / \mathrm{v})$ acetone (negative control), and compound $1(0.16 \mathrm{mM})$ were added to each well. The mixtures were incubated at $22^{\circ} \mathrm{C}$ for six hours. B. cinerea hyphae adhered to glass coverslips were washed three times with liquid minimum medium and stained with fluorochrome calcofluor white. After $10 \mathrm{~min}$ of incubation, the hyphae were washed with minimum medium and glass coverslips containing hyphae were mounted in slides. For the assembly of the samples in the slides, $15 \mu \mathrm{L}$ of DABCO (1,4-diazabicyclo[2.2.2]octane) was used. The fluorescence of $B$. cinerea hyphae stained with fluorochrome calcofluor white was observed under a fluorescence microscope, Blue/Violet (110033V2) filter was used. These experiments were done at least in triplicate.

\subsection{Effect on the plasmatic membrane integrity of $B$. cinerea.}

This was determined using the SYTOX Green uptake assay ${ }^{26}$. B. cinerea conidia at a final concentration of $1 \times 10^{5}$ conidia $\mathrm{mL}^{-1}$ were inoculated in 24-well plates (lined with 12-mm glass coverslips) containing $1 \mathrm{~mL}$ of liquid minimum medium. Cultures were incubated at $22^{\circ} \mathrm{C}$ for $15 \mathrm{~h}$ to permit the germination of the conidia. After this time, liquid medium was removed. Afterwards, liquid medium containing: $70 \%(\mathrm{v} / \mathrm{v})$ ethanol (positive control), $10 \%(\mathrm{v} / \mathrm{v})$ acetone (negative control), and compound $\mathbf{1}(0.16 \mathrm{mM})$ were added to each well. The mixtures were incubated at $22^{\circ} \mathrm{C}$ for six hours. $B$. cinerea hyphae adhered to glass coverslips were washed three times with liquid minimum medium and stained with $50 \mathrm{nmol} \mathrm{L}^{-1}$ SYTOX Green. After $10 \mathrm{~min}$ of incubation, the hyphae were washed with minimum medium and glass coverslips containing hyphae were mounted in slides. For the assembly of the samples in the slides, $15 \mu \mathrm{L}$ of DABCO was used. The fluorescence of $B$. cinerea hyphae stained with SYTOX Green was observed under a confocal microscope (Carl Zeiss LSM 510) at an excitation wavelength of $488 \mathrm{~nm}$ and an emission wavelength of $540 \mathrm{~nm}$. Each experiment was done at least three times.

\subsection{Experimental design and statistical analyses.}

The antifungal activity of the different compounds against $B$. cinerea was analyzed with a one-way analysis of variance (Prism 5.01). Means were separated with the least significant difference test $(\mathrm{P}<0.05)$.

\section{RESULTS AND DISCUSSION}

\subsection{Synthesis of heterodimeric compound}

The reaction catalyzed by the laccase from $T$. versicolor among syringic acid and aniline revealed the formation of a main product (compound 1) and a secondary product. Therefore, this laccase was able to mediate the coupling of syringic acid with aniline, similar to the reactions of other anilines, such as 4-chroloaniline ${ }^{27}$ and 4-aminobenzoic acid ${ }^{18}$.

To increase yield in the production of compound 1, two variables were considered: substrate ratio (syringic acid:aniline) (Table 1) and the amount of the enzyme (Table 2). For substrate ratios 1:1 and 1:2, no difference in the yield was observed. But when ratio was 2:1, the yield dropped to about half.

Table 1. Purification yields of products at different reactant ratios.

\begin{tabular}{|c|c|}
\hline $\begin{array}{c}\text { Substrate ratio } \\
\text { (syringic acid:aniline) }\end{array}$ & Purification yield (\%) \\
\hline $1: 1$ & 41.3 \\
\hline $1: 2$ & 39.2 \\
\hline $2: 1$ & 18.5 \\
\hline
\end{tabular}

On the other, the yield in compound 1 production increased when the amount of the enzyme was increased. Consequently, a better yield for compound 1 production was obtained using a reactant ratio of 1:1 and $9 \mathrm{U}$ of laccase. In this reaction conditions, the laccase-mediated reaction among syringic acid and aniline formed the product with a yield of $67.8 \%$.

Bollag et al. ${ }^{28}$ synthesized the dimer N-(2,6-diethylphenyl)-2,6dimethoxy-p-benzoquinone imine with a higher yield (around 85\%) using the enzyme laccase isolated from the fungus Rhizoctonia praticola as catalyzer and syringic acid and 2,6-diethylaniline as substrates. They observed that yield increased with the concentration of syringic acid ${ }^{28}$. On the contrary, in this work, it can be observed that the yield dropped to $18.5 \%$ when the concentration of syringic acid was increased. The different yields in dimer production could be attributed to differences in reaction conditions and also in the laccase used. It has been reported that these enzymes have different optimal $\mathrm{pH}$, and the products formed may vary using a different $\mathrm{pH}$ in the reaction ${ }^{29}$.

Table 2. Purification yields of products at different enzyme amounts.

\begin{tabular}{|c|c|}
\hline Amount of laccase (U) & Purification yield (\%) \\
\hline 2.25 & 35.1 \\
\hline 4.5 & 41.3 \\
\hline 9 & 67.8 \\
\hline
\end{tabular}

After purification by semi-preparative thin layer chromatography, compound 1 was analyzed by ${ }^{1} \mathrm{H}$ and ${ }^{13} \mathrm{C}$ NMR spectroscopy. The recorded ${ }^{1} \mathrm{H}$ NMR spectrum showed differences with the spectra of the precursor molecules. Aniline spectrum displayed three aromatic signals $(\delta 7.16 \mathrm{t}(J=7.8 \mathrm{~Hz}), 6.76$ $\mathrm{t}(J=7.4 \mathrm{~Hz})$, and $6.69 \mathrm{~d}(J=7.6 \mathrm{~Hz}))$, the product has the same aromatic signals with identical multiplicity of the aniline $\delta 7.41 \mathrm{t}(J=7.8 \mathrm{~Hz}), \delta 7.18 \mathrm{t}$ $(J=7.4 \mathrm{~Hz})$, and $\delta 6.9 \mathrm{~d}(J=7.4 \mathrm{~Hz})$. However, it presented different chemical shifts, due to a different chemical environment produced by the quinone ring. The spectrum of the other precursor molecule (syringic acid) showed only one aromatic signal $(\delta 7.35 \mathrm{~s})$, but in the synthesized product, this signal disappeared and two new signals appeared $(\delta 6.158 \mathrm{~d}(J=2.0 \mathrm{~Hz})$ and $6.423 \mathrm{~d}$ $(J=2.0 \mathrm{~Hz}))$ this coupling constant suggests a 4-bond coupling ${ }^{30}$. These signals belong to the two protons of the quinone-imine ring. The spectral data agree with a similar compound previously reported in the literature ${ }^{28}$. Therefore, the two protons have different chemical environments and this was also observed for the methoxyl groups. The ${ }^{13} \mathrm{C}$ NMR spectrum exhibited twelve signals: aromatic signals (between $\delta 115$ and 160), $\mathrm{C}=\mathrm{C}$ signals (between $\delta 100$ and $140)$, methoxyl signals $\delta 57.076$ and 57.351 and finally, and carbonilic carbon signal ( $\delta$ 177).

In order to determine the molecular structure of the synthesized product and to assign all the ${ }^{1} \mathrm{H}$ and ${ }^{13} \mathrm{C}$ signals, ${ }^{1} \mathrm{H}-{ }^{13} \mathrm{C}$ HSQC and ${ }^{1} \mathrm{H}-{ }^{13} \mathrm{C}$ HMBC experiments were performed (results now shown). All these findings suggested that they belong to a six carbon quinone-ring. Mass spectral analysis of the compound showed a molecular ion peak $\left(\mathrm{M}^{+} \mathrm{m} / \mathrm{z}=243\right)$ corresponding to 
the compound shown in figure 1 according to formula $\mathrm{C}_{14} \mathrm{H}_{13} \mathrm{NO}_{3}$ Therefore, compound 1 was identified as 2,6-dimethoxy-4-(phenylimino)benzenone (Figure 1), this quinone-imine like compound has not been reported previously in the literature. In a previous work, the laccase-mediated reaction between syringic acid and $\mathrm{p}$-chloroaniline was described ${ }^{27}$. These authors suggested that the mechanism of the reaction was through a nucleophilic addition to quinone structures ${ }^{27}$. On the other hand, Mikolasch et al. ${ }^{8}$ presumed that the laccase reactions proceed by formation of a radical cation, following by a deprotonation of the hydroxyl group to give the radical. Further investigation is needed to describe the reaction mechanism in the synthesis of compound 1 .

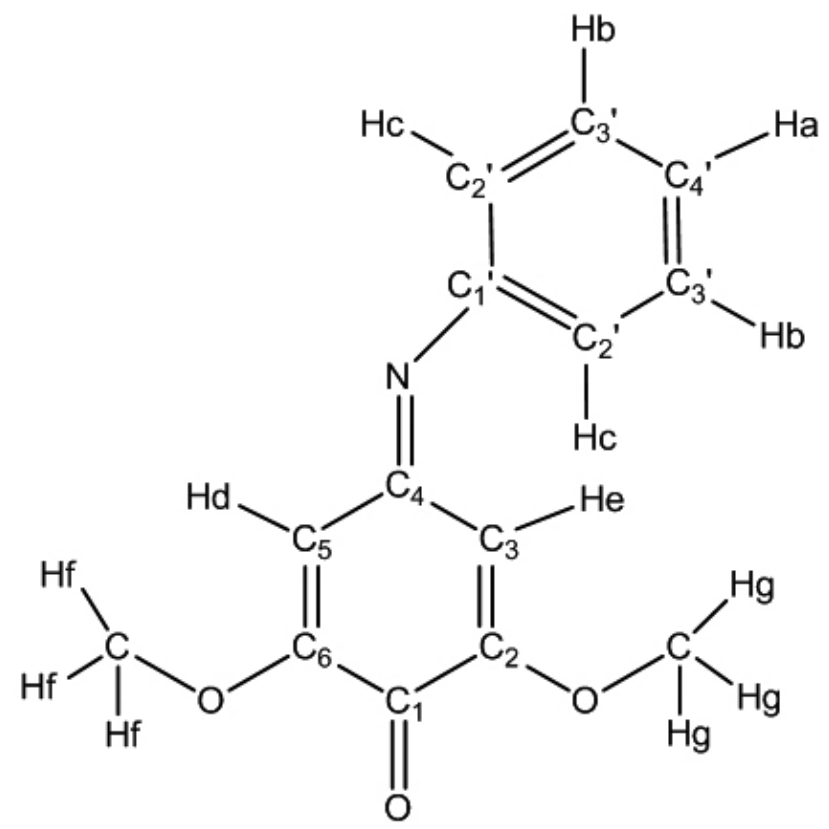

Figure 1. Structure of compound 1 (2,6-dimethoxy-4-(phenylimino) benzenone)

3.2. Antifungal activity of the compound 1, the syringic acid and the aniline

In order to determine the antifungal activity of compound 1, syringic acid, and aniline against $B$. cinerea, the effect on mycelial growth and conidial germination was evaluated in solid medium.

Compound 1 showed a higher antifungal effect on the mycelial growth of $B$. cinerea than the substrates (Table 3), these differences are statistically significant $(P<0.05)$. This compound inhibited mycelial growth, with an $\mathrm{IC}_{50}$ value of $0.14 \mathrm{mM}$. The commercial fungicide iprodione was also tested; the results showed that this fungicide had a higher antifungal activity than compound 1 .

Table 3. Effect of compound 1, syringic acid, and aniline on the mycelial growth of $B$. cinerea in a solid medium.

\begin{tabular}{|c|c|}
\hline Compound & $\mathrm{IC}_{50}(\mathrm{mM})^{*}$ \\
\hline Syringic acid & $3.97 \pm 0.52 \mathrm{a}$ \\
\hline Aniline & $2.14 \pm 0.31 \mathrm{~b}$ \\
\hline Compound $\mathbf{1}$ & $0.14 \pm 0.02 \mathrm{c}$ \\
\hline Iprodione & $0.015 \pm 0.003 \mathrm{~d}$ \\
\hline
\end{tabular}

* $\mathrm{IC}_{50}$ was determined after 4 days of incubation. Data represents mean \pm standard deviation of three independent experiments. Different letters indicate that the means are significantly different at $P<0.05$.

Figure 2 shows the effect of compound 1 on the conidial germination of $B$. cinerea. At a concentration of $0.16 \mathrm{mM}$, compound 1 delayed the beginning of the conidial germination by two hours compared to the control.

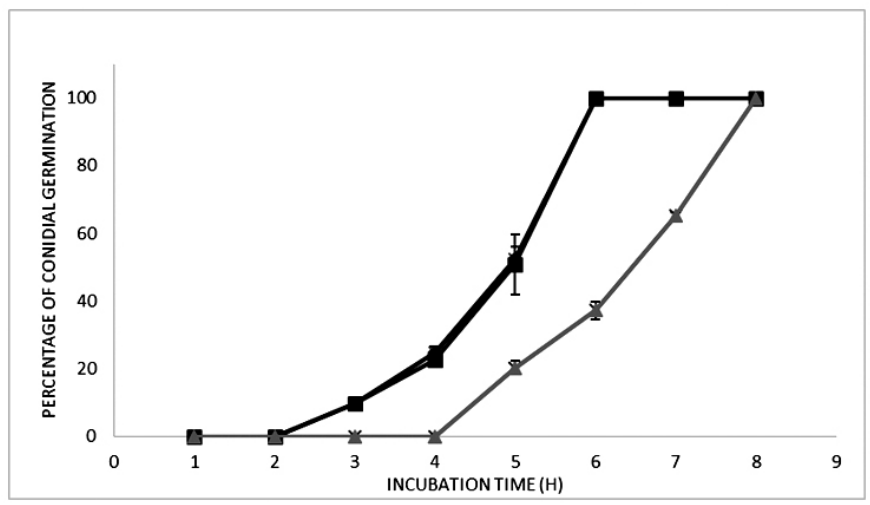

Figure 2. Effect of compound 1 on the conidial germination of $B$. cinerea. Compound 1, dissolved in acetone, was added at final concentration of $0.16 \mathrm{mM}$

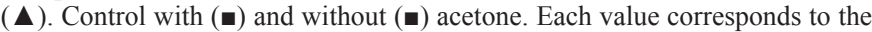
average of two independent experiment \pm standard deviations.

There are no previous works on antifungal effect of quinone-imines against fungal species neither against $B$. cinerea; nevertheless, the cytotoxic activity of a similar quinone-imine has been extensively reported, mainly by its reaction with proteins ${ }^{31,32}$. However, antifungal activity of quinones has been analyzed; Mendoza et al. ${ }^{33}$ reported the antifungal effect of various quinones on mycelial growth and conidia germination of $B$. cinerea. A similar effect was observed for the compound synthesized in this study. The $\mathrm{IC}_{50}$ values for the reported quinones were among $0.125 \mathrm{mM}$ and $0.71 \mathrm{mM}$, similar to the $\mathrm{IC}_{50}$ obtained for compound $1,0.14 \pm 0.02 \mathrm{mM}$. In regard to conidial germination, both the reported quinones and compound 1 showed a delay at the beginning of the process.

Laccase-mediated modification of phenolic compounds has been previously reported with the objective of increase a higher biological activity. For instance, the ferulic acid was modified using laccase to produce two dimeric molecules with higher antioxidant capacity than the ferulic acid ${ }^{16}$. An additional example is the enzymatic modification of antibiotics using nitrogen compounds, the products showed higher antibiotic activity than the initial antibiotic ${ }^{20,21}$. Similarly, in this study, the enzymatic modification of syringic acid with aniline increased its antifungal activity.

\subsection{Effect on cell wall of $B$. cinerea.}

The redox properties of some quinones have been described. These are able to generate reactive oxygen species causing damage to several macromolecules like membrane lipids, DNA, and proteins ${ }^{34}$. According to this, the effect of compound 1 on the membrane integrity was measured using SYTOX Green nucleic acid stain, fluorescence of the nuclei is only observed when the plasma membrane is damaged, and SYTOX is able to enter to the hypha ${ }^{26}$, however, after the incubation with compound 1, no fluorescence was detected (results not shown).

Afterwards, the effect of compound 1 on the cell wall was tested using the fluorochrome calcofluor white which binds to $\beta-1,3$ and $\beta-1,4$ polysaccharides, such as chitin, one of the main components of the cell wall in fungi, and when this occurs, fluorescence of the hyphae could be observed ${ }^{35}$. In the negative control, (acetone), intense fluorescence was observed, indicating no damage of the cell wall (Figure 3, row A), when hyphae were treated with lysing enzymes (positive control) only a small amount of fluorescence was observed, indicating a damaged cell wall (Figure 3, row B). When hyphae were treated with compound 1 , fluorescence was lower than the observed in the negative control (Figure 3, row $\mathrm{C}$ ), indicating an alteration of $B$. cinerea cell wall.

Therefore, compound 1 would interact with cell wall of $B$. cinerea and it would not cause damage in the plasmatic membrane.

\section{CONCLUSIONS}

In this study, the antifungal activity of syringic acid was improved using the enzyme laccase to synthesize the compound 2,6-dimethoxy-4(phenylimino)benzenone by the coupling reaction with aniline. This compound has not been reported previously. Subsequently, the laccase modification is a good alternative to improve the antifungal activity found in grape pomace. Cell wall damage was observed when the fungus was incubated with compound 1. 


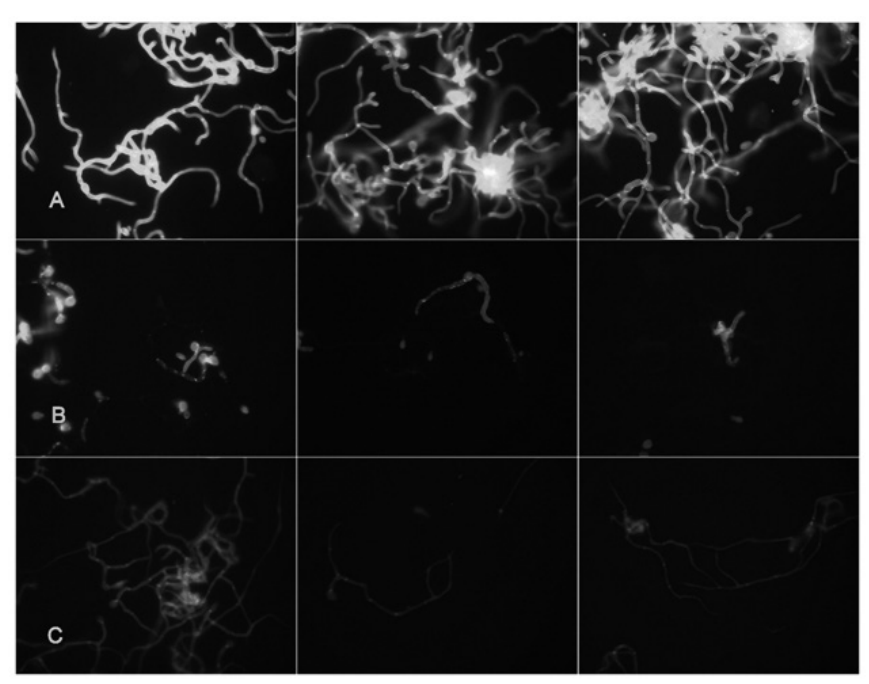

Figure 3. Effect of compound 1 on the cell wall integrity of $B$. cinerea. Conidia at a final concentration of $1 \times 10^{5}$ conidia $\mathrm{mL}^{-1}$ were inoculated in liquid minimum medium at $22^{\circ} \mathrm{C}$ for $15 \mathrm{~h}$ in the presence of $10 \%(\mathrm{v} / \mathrm{v})$ acetone (row A), Lysing enzymes (row B), and $0.16 \mathrm{mM}$ of compound $\mathbf{1}$ (row C). Each row shows three different microscope fields of the same treatment.

\section{ACKNOWLEDGMENTS}

The authors thank FONDECYT 1130389 and DICYT for their financial support.

\section{REFERENCES}

1. Leroux, P. Chemical control of Botrytis and its resistance to chemical fungicides. In Botrytis: Biology, pathology and control; Elad, Y.; Williamson, B.; Tudzynski, P.; Delen, N., Eds.; Springer: Dordrecht, Netherlands, 2007; pp. 195-217.

2. M. A. Jacometti, Wratten, S. D. Walter. Aust. J. Grape Wine Res. 2010, 16, 154-172.

3. R. J. Grayer, J. B. Harborne, Phytochemistry 1994, 37, 19-42.

4. A. E. Osbourn, Plant Cell 1996, 8, 1821-1831.

5. J. B. Harborne, Biochem. Syst. Ecol. 1999, 27, 335-367.

6. I. S. Arvanitoyannis, D. Ladas, A. Mavromatis, Int. J. Food Sci. Technol. 2006, 41, 475-487.

7. L. Mendoza, K. Yañez, M. Vivanco, R. Melo, M. Cotoras, Ind. Crops Prod. 2013, 43, 360-364.

8. A. Mikolasch, F. Schauer, Appl. Microbiol. Biotechnol. 2009, 82, 605-24.

9. K. Manda, D. Gördes, A. Mikolasch, E. Hammer, E. Schmidt, K. Thurow, F. Schauer, Appl. Microbiol. Biotechnol. 2007, 76, 407-16.

10. T. H. J. Niedermeyer, A. Mikolasch, M. Lalk, J. Org. Chem. 2005, 70, 2002-8.

11. T. Kudanga, G. S. Nyanhongo, G. M. Guebitz, S. Burton, Enzyme Microb. Technol. 2011, 48, 195-208.

12. J. Ihssen, M. Schubert, L. Thöny-Meyer, M. Richter, PLoS One 2014, 9 , e89924.

13. O. V. Morozova, G. P. Shumakovich, M. A. Gorbacheva, S. V. Shleev, A. I. Yaropolov, . Biochemistry 2007, 72, 1136-1150.

14. U. Jonas, E. Hammer, E. T. K. Haupt, F. Schauer, Arch. Microbiol. 2000, 174, 393-398.

15. T. Shiba, L. Xiao, T. Miyakoshi, C. Chen, J. Mol. Catal. B Enzym. 2000 $10,605-615$.

16. O. E. Adelakun, T. Kudanga, A. Parker, I. R. Green, M. le Roes-Hill, S. G. Burton,. J. Mol. Catal. B Enzym. 2012, 74, 29-35.

17. S. Witayakran, A. J. Ragauskas, Adv. Synth. Catal. 2009, 351, 1187-1209.

18. V. Ibrahim, N. Volkova, S. H. Pyo, G. Mamo, R. Hatti-Kaul, J. Mol. Catal. B Enzym. 2013, 97, 45-53.

19. A. Mikolasch, T. H. J. Niedermeyer, M. Lalk, S. Witt, S. Seefeldt, E. Hammer, F. Schauer, M. Gesell, S. Hessel, W. D. Jülich, U. Lindequist, Chem. Pharm. Bull. (Tokyo). 2006, 54, 632-638.

20. A. Mikolasch, S. Hessel, M. G. Salazar, H. Neumann, K. Manda, D. Gordes, E. Schmidt, K. Thurow, E. Hammer, U. Lindequist, M. Beller, F.
Schauer, D. Gōrdes, Chem. Pharm. Bull. 2008, 56, 781-786.

21. A. Mikolasch, T. H. J. Niedermeyer, M. Lalk, S. Witt, S. Seefeldt, E. Hammer, F. Schauer, M. Gesell Salazar, S. Hessel, W.-D. Jülich, U. Lindequist, Chem. Pharm. Bull. (Tokyo). 2007, 55, 412-6.

22. K. W. Wellington, N. I. Kolesnikova, Bioorg. Med. Chem. 2012, 20 , 4472-81.

23. G. Muñoz, P. Hinrichsen, Y. Brygoo, T. Giraud, Mycol. Res. 2002, 106, 594-601.

24. L. Mendoza, P. Espinoza, A. Urzua, M. Vivanco, M. Cotoras, Molecules 2009, 14, 1966-1979.

25. M. Cotoras, L. Mendoza, A. Muñoz, K. Yáñez, P. Castro, M. Aguirre, Molecules 2011, 16, 3885-3895.

26. K. Thevissen, F. R. G. Terras, F. Willem, Appl. Environ. Microbiol. 1999, $65,5451-5458$.

27. K. Tatsumi, A. Freyer, R. D. Minard, Soil Biol. Biochem. 1994, 26, 135142.

28. J. M. Bollag, R. D. Minard, S. Y. Liu, Environ. Sci. Technol. 1983, 17, $72-80$.

29. A. Leonowicz, R. U. Edgehili, J. M. Bollag. Arch. Microbiol. 1984, 137, 89-96.

30. H. Guenther, G. Jikeli, Chem. Rev. 1977, 77, 599-637.

31. L. P. James, P. R. Mayeux, J. A. Hinson, Drug Metab. Dispos. 2003, 31, 1499-1506.

32. Y. Jan, D. E. Heck, A. Dragomir, C. R. Gardner, D. L. Laskin, Chem. Res. Toxicol. 2014, 27, 882-894.

33. L. Mendoza, R. Araya-Maturana, W. Cardona, T. Delgado-Castro, C. García, C. Lagos, M. Cotoras, J. Agric. Food Chem. 2005, 53, 10080-4.

34. J. L. Bolton, M. Trush, T. M. Penning, G. Dryhurst, T. J. Monks, Chem. Res. Toxicol. 2000, 13, 135-60.

35. W. Herth, E. Schnepf, Protoplasma 1980, 105, 129-133. 